\title{
Assessment of dispersal and population structure of Norway rats (Rattus norvegicus) in a seaport setting
}

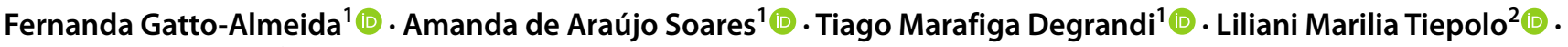 \\ Florian Pichlmueller ${ }^{3,4}$ - Iris Hass ${ }^{1}(\mathbb{D}$
}

Accepted: 21 September 2021 / Published online: 6 October 2021

(c) The Author(s) 2021

\begin{abstract}
Seaports are introduction hotspots for invasive alien species (IAS). This is especially true for rodents, which have accompanied humans around the globe since the earliest days of ocean-going voyages. The rapid spread of IAS soon after arrival in a new environment is facilitated by further human-mediated transport or landscape features, like roads. By measuring genetic diversity and structure to investigate dispersal pathways, we gained insight into the transport, spread and establishment stages of a biological invasion, leveraging the most common rodent species ( $R$. norvegicus) in this setting. We characterized the genetic structure of three Norway rat populations along a busy industrial road used by trucks to access the Port area in Paranaguá city (Brazil). A total of 71 rats were genotyped using 11 microsatellite markers. The results revealed a pattern of gene flow contrary to the expected stepping-stone model along the linear transect, with the two furthest apart populations being clustered together. We hypothesize that the observed outcome is explained by natural dispersal along the corridor being lower than human-mediated transport. The sampled area furthest from the port is a gas station frequented by trucks which are considered the most likely mode of transportation. In terms of management strategies, we suggest more emphasis should be put on cargo surveillance to lower the risk of Norway rat dispersal, not only for biosecurity, but also for sanitary reasons, as this port is a major grain trading point.
\end{abstract}

Keywords Human-mediated dispersal $\cdot$ Microsatellite $\cdot$ Road $\cdot$ Invasive $\cdot$ Urban areas $\cdot$ Zoonotic disease

\section{Introduction}

Biological invasions are a serious threat to biodiversity around the world, causing not only disturbances to ecosystems, but also threats to human health and negative impacts on agriculture (Myers et al. 2000; Miller et al. 2016). By definition, invasions occur when species are intentionally

Florian Pichlmueller and Iris Hass authors are joint senior authors

Fernanda Gatto-Almeida

fgattoalmeida@ymail.com

1 Department of Genetics, Universidade Federal Do Paraná, Private Bag 19071, Curitiba, PR 81531-990, Brazil

2 Laboratory of Biodiversity and Conservation, Universidade Federal Do Paraná, Matinhos, Brazil

3 School of Biological Sciences, University of Auckland, Private Bag 92019, Auckland 1142, New Zealand

4 Genomics Aotearoa and School of Biomedical Sciences, University of Otago, Dunedin 9054, New Zealand or accidentally introduced outside of their native or historic range, and successfully spread in the new environment (Levine 2008).

Rodents, especially from the genus Rattus, are commensal species considered to be the most widely introduced vertebrates, accompanying humans around the globe (Drake and Hunt 2009). Their occurrence often has a dramatic impact on native biodiversity, affecting individual demographic rates, genetic (through hybridization), trophic structure and/or resources availability (Parker et al. 1999), and they are causing massive economic loss because of destruction of grains and stocked materials (Pimentel et al. 2000). Rodents are also known for their role in facilitation of the transmission of numerous diseases to humans (Himsworth et al. 2013). These animals are particularly problematic because of their high reproductive rate, the capability of exploiting a wide range of food sources, survival in vastly different ecological conditions and ability to travel long distances unnoticed, utilising existing transportation infrastructure and shipping routes (Varnham 2010). 
Seaports are considered introduction epicentres for invasive alien species (IAS) (Drake and Lodge 2004; Miller et al. 2016). It is therefore crucial that ports implement surveillance measures, such as containment facilities and the use of biocontrol agents, chemicals (toxins) or mechanical devices (traps), to control, and prevent the establishment and spread of alien species in a new environment (Lodge et al. 2006; Gren 2008).

Paranaguá is a seaport city located in Paraná state and is home to the main port of Southern Brazil. The port of Paranaguá is the second largest port in export of grains, fruits, and seeds in Brazil handling 13\% of the national cargo and it is the third-largest port in cereal shipment (i.e. considering the volume imported and exported) (11.3\% of the national cargo) (ANTAQ 2020). Because of the high volumes of food being handled and the resulting abundance of food sources for pest species, Paranaguá has long dealt with pest infestations. The port has implemented a vector proliferation control program that aims to reduce and control pigeon, rat, and mice populations by using poison bait and bird repellent. In addition, to reduce the food availability for pest species, cleaning procedures are in place to remove spilled grains in the primary area of loading/unloading and surroundings (APPA 2016). There is no information about how effective these measures are in terms of avoid spreading of these pests to the city.

Previous studies made in urban environment show that Rattus norvergicus present strong site fidelity and individual movements are usually limited to $30-150 \mathrm{~m}$. Also, dispersal from their natal site seems to occur over short distances (Gardner-Santana et al. 2009; Byers et al. 2019). If that applies to the rat population in Paranaguá, the control measures implemented in the Port should be enough to avoid spread of new immigrants that arrive in the port. If an IAS manages to pass through the implemented control measures after its arrival in the new environment, linear features in the landscape, like roads, railways, and canals can facilitate its spread and colonization (Brown et al. 2006; Cameron and Bayne 2009). In Paranaguá a sampling collection through the city revealed a positive association of Norway rats (Rattus norvegicus) with the main roads used by trucks to access the Port area (Gatto-Almeida et al. 2020a). In this study we aimed to evaluate how effective are the control measures implemented by Paranaguá's port to prevent rats spread from the port. For this purpose, we genetically characterize three $R$. norvegicus putative populations along the main road used by trucks in Paranaguá i.e. a linear feature that may be facilitating their spread, to understand possible migrations and gene flow that might be occuring. This road crosses the entire city on its longest axis connecting its main entrance to the port. If the control measures were effective we expected individuals from the two areas outside the port would be genetically similar between them, and port's population would present higher genetic differentiation.

\section{Material and methods}

\section{Study area}

The study was conducted in Paranaguá municipality $\left(25^{\circ} 30^{\prime} 31^{\prime \prime} \mathrm{S} 48^{\circ} 30^{\prime} 39^{\prime \prime} \mathrm{W}\right)$, a port city with a population of 153.600 , and $827 \mathrm{~km}^{2}$ area, located in Paraná state, South of Brazil (Fig. 1). The port's history dates back to 1872, when it was initially used as a berth, until its official foundation in 1935. It has an organized area of $425 \mathrm{~km}^{2}$, and is the most important port in south Brazil, moving mainly solid bulk (34 million tons in 2019), but also liquid bulk, and containers (ANTAQ 2020; APPA 2019).

\section{Sample collection}

Considering some limiting factors we had to carry out the study (e.g. stolen traps, safety and financial resources), we selected three locations to survey in Paranaguá. Norway rat tissue samples were collected from these three locations along the main road used by trucks to transport goods, which we a priori treated as population units. Samples were obtained from rat carcasses found in the respective areas, or from individuals captured by trapping. We performed nine field campaigns between January 2017 and July 2018, and applied a total effort of 535 trap-nights. Rats were captured in live traps and euthanized for tissue collection following the procedures recommended by UFPR ethics committee (CEUA No 1211).

We were interested in characterizing gene flow along the road leading away from the port, and for that purpose we selected three sampling sites in Avenida Ayrton Senna da Silva (Fig. 1, black line). The first sampling location was the Port complex (Fig. 1, cyan circles). Through the establishment of a partnership with the port administration (Administração dos Portos de Paranaguá e Antonina - APPA), we were able to access rat carcasses collected inside the Port area by the zoonosis control team and installed live traps in areas where we had access. For comparison of genetic diversity along the road, rats were sampled in an area $\sim 2 \mathrm{~km}$ away from the Port (Area 2) chosen because of the presence of wasteland, residences and a big storage courtyard (Fig. 1, red squares). The third area (Area 3 ) was $\sim 6 \mathrm{~km}$ away from the Port and was chosen because of a gas station, where truckers regularly stay overnight, and surrounded by wasteland and residences (Fig. 1, purple triangles). Both Area 2 and 3 had grassy berms along the road where traps were set and the carcasses were found. 
Fig. 1 Location of the study sites in Paranaguá, Paraná state, Brazil. Geometric shapes represent the approximated location where each sample was collected
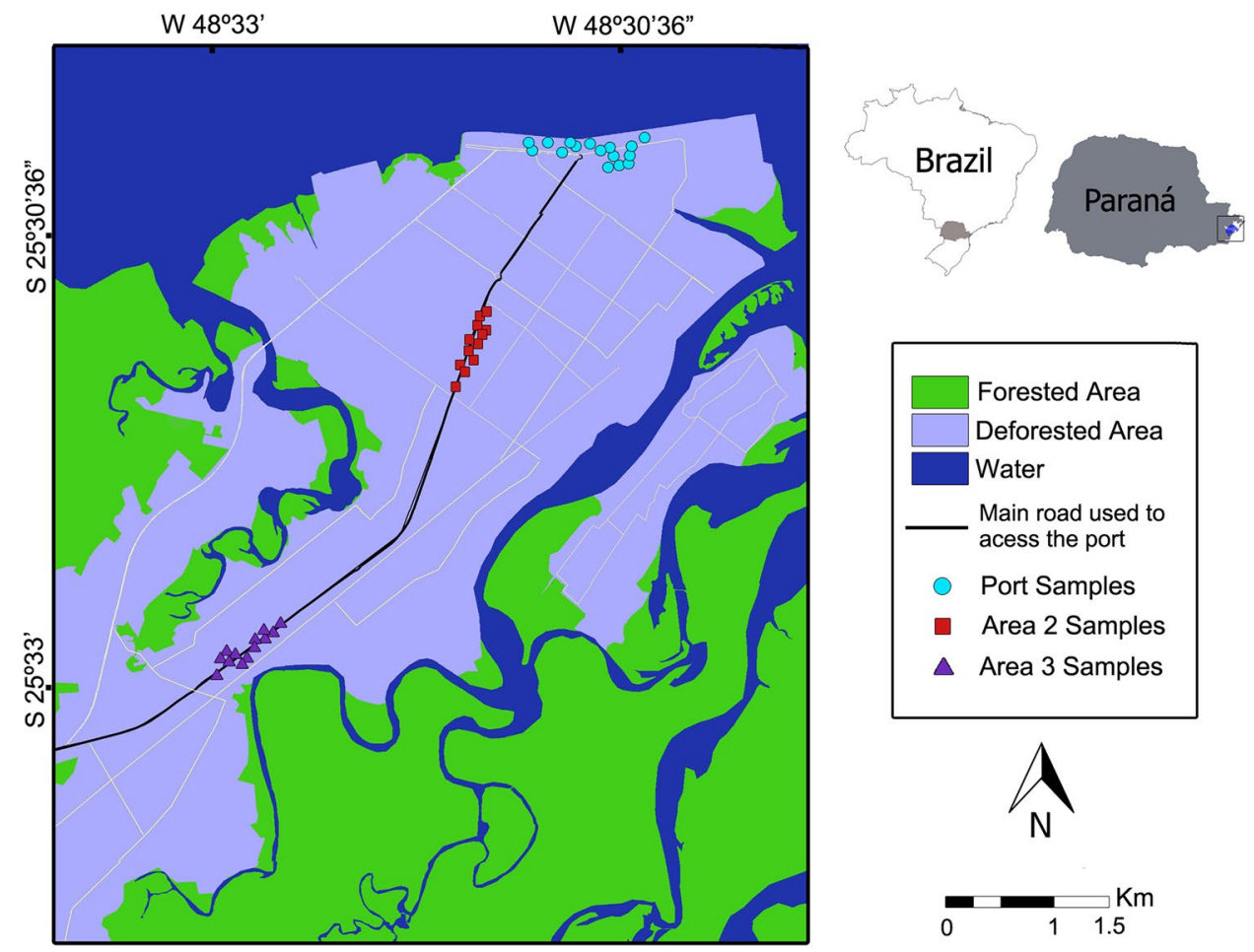

Samples were obtained under License $N^{\circ} 23,102-1$ SIS$\mathrm{BIO}$ from the Brazilian environmental agency.

\section{DNA extraction, genotyping, and sequencing}

Genomic DNA extractions were done from muscle tissue samples preserved in $70 \%$ ethanol. We used 11 microsatellite markers developed by Jacob et al. (1995) from Rattus norvegicus: D12Rat4, D5Rat83, D7Rat13, D9Rat13, D10Rat20, D16Rat81, D11Mgh5, D15Rat77, D2Rat234, D18Rat96, and D20Rat46. Markers were chosen from different chromosomes to avoid physical linkage. The M13 fluorescent labeling protocol (Schuelke 2000) was used to amplify the loci and incorporate the fluorescent dyes 6-FAM, and NED (Integrated DNA Technologies®).

Polymerase chain reactions (PCR) were performed in $15 \mu \mathrm{l}$ volumes containing $2 \mu \mathrm{l}$ of extracted DNA (> $60 \mathrm{ng}$
DNA/ $\mu \mathrm{l}), 1 \mathrm{X}$ Buffer, $1.5 \mathrm{mM} \mathrm{MgCl}_{2}, 0.2 \mathrm{mM}$ dNTPs, $0.1 \mu \mathrm{M}$ of forward primer, $0.2 \mu \mathrm{M}$ of each reverse and M13labelled primer, and $1 \mathrm{U}$ Taq. The thermocycler conditions were: initial denaturation of $94^{\circ} \mathrm{C}$ for $5 \mathrm{~min}, 25$ cycles of $94^{\circ}$ for $45 \mathrm{~s}, 55^{\circ} \mathrm{C}$ for $50 \mathrm{~s}$ and $72^{\circ} \mathrm{C}$ for $50 \mathrm{~s}$, followed by 8 cycles of $94^{\circ}$ for $45 \mathrm{~s}, 53^{\circ} \mathrm{C}$ for $40 \mathrm{~s}$ and $72^{\circ} \mathrm{C}$ for $50 \mathrm{~s}$, and final extension of $72^{\circ} \mathrm{C}$ for $15 \mathrm{~min}$.

PCR products were mixed with $0.4 \mu \mathrm{L}$ of GeneScan ${ }^{\mathrm{TM}}$ 600 LIZ® (Applied Biosystems) and 7,6 $\mu \mathrm{L}$ of Hi-Di Formamide (Applied Biosystems), followed by heat shock treatment, $95^{\circ} \mathrm{C}$ for $5 \mathrm{~min}, 4^{\circ} \mathrm{C}$ for $5 \mathrm{~min}$. Genotyping runs were performed on an ABI3500 (Applied Biosystems) automated sequencer and analysed using GENEIOUS prime version 2019.0.4 (https://www.geneious.com) including the Microsatellite Analysis External Plugin version 1.4.6 (Biomatters Ltd.) Only individuals with at least six genotyped loci were kept in the dataset for analysis.
Table 1 Measures of genetic diversity per sampling location. Sampling location, number of sampled individuals $\left(\mathrm{N}_{\mathrm{S}}\right)$, number of alleles reported for 11 loci $\left(\mathrm{N}_{\mathrm{A}}\right.$ ), allelic richness (Ar) (Ar; based on min. sample size of 13 individuals), private alleles (PA), within population gene diversity $\left(\mathrm{H}_{\mathrm{S}}\right)$, and observed heterozygosity $\left(\mathrm{H}_{\mathrm{O}}\right.$ derived from $\mathrm{H}_{\mathrm{S}}$ and $\mathrm{F}_{\mathrm{IS}}$ values as $\mathrm{H}_{\mathrm{O}}=\mathrm{H}_{\mathrm{S}}-\left(\mathrm{F}_{\mathrm{IS}} \times \mathrm{H}_{\mathrm{S}}\right)$ ), $\mathrm{F}_{\mathrm{IS}}$ values (none were significant, based on 21,000 randomisations)

\begin{tabular}{llllllrr}
\hline & $\mathrm{N}_{\mathrm{S}}$ & $\mathrm{N}_{\mathrm{A}}$ & $\mathrm{Ar}$ & $\mathrm{PA}$ & $\mathrm{H}_{\mathrm{S}}$ & $\mathrm{H}_{\mathrm{O}}$ & $\mathrm{F}_{\mathrm{IS}}$ \\
\hline Port & 25 & 79 & 6.528 & 18 & 0.782 & 0.784 & -0.003 \\
Area 2 & 24 & 66 & 5.430 & 4 & 0.708 & 0.672 & 0.051 \\
Area 3 & 22 & 76 & 6.158 & 13 & 0.730 & 0.702 & 0.038 \\
\hline
\end{tabular}


Table 2 Measures of genetic diversity per locus. Number of alleles $\left(\mathrm{N}_{\mathrm{A}}\right)$, allelic richness (Ar; based on min. sample size of 13 individuals), observed heterozygosity $\left(\mathrm{H}_{\mathrm{O}}\right)$ and intrapopulation gene diversity $\left(\mathrm{H}_{\mathrm{S}}\right)$ according to Nei (1987), mean pairwise $\mathrm{F}_{\mathrm{ST}}$ and $\mathrm{F}_{\mathrm{IS}}$ for each locus following Weir and Cockerham (1984) (*** indicates significance $\mathrm{p}<0.001, * * \mathrm{p}<0.01$ and $* \mathrm{p}<0.05$, based on 21,000 randomisations)

\begin{tabular}{llllllc}
\hline Locus Name & $\mathrm{N}_{\mathrm{A}}$ & $\mathrm{Ar}$ & $\mathrm{H}_{\mathrm{O}}$ & $\mathrm{H}_{\mathrm{S}}$ & $\mathrm{F}_{\mathrm{ST}}$ & $\mathrm{F}_{\mathrm{IS}}$ \\
\hline D5Rat83 & 12 & 7.743 & 0.685 & 0.757 & $0.12 * * *$ & 0.105 \\
D10Rat20 & 10 & 6.935 & 0.706 & 0.747 & $0.028 * * *$ & 0.046 \\
D2Rat234 & 8 & 6.540 & 0.768 & 0.78 & $0.073 * * *$ & 0.019 \\
D20Rat46 & 10 & 6.187 & 0.723 & 0.731 & $0.057 * * *$ & 0.028 \\
D11Mgh5 & 9 & 4.396 & 0.692 & 0.588 & $0.117 * * *$ & -0.181 \\
D7Rat13 & 13 & 9.516 & 0.773 & 0.829 & $0.069 * * *$ & 0.065 \\
D16Rat81 & 14 & 9.174 & 0.782 & 0.839 & $0.053 * * *$ & 0.07 \\
D18Rat96 & 11 & 8.289 & 0.783 & 0.782 & $0.083 * * *$ & -0.004 \\
D9Rat13 & 7 & 5.351 & 0.675 & 0.709 & $0.027 * *$ & 0.043 \\
D15Rat77 & 7 & 5.280 & 0.774 & 0.726 & 0.01 & -0.063 \\
D12Rat4 & 7 & 4.301 & 0.548 & 0.649 & $0.032 * *$ & $0.158 *$ \\
Mean & 9.82 & 6.701 & 0.719 & 0.740 & &
\end{tabular}

\section{Data analysis}

The software Micro-Checker version 2.2.3 (Van Oosterhout et al. 2004) was used to test for the presence of null alleles, false alleles and allelic dropout across the sampling sites data, using Bonferroni correction, and 3,000 randomisations.

The number of alleles $\left(\mathrm{N}_{\mathrm{A}}\right)$, allelic richness $(\mathrm{Ar})$, observed heterozygosity $\left(\mathrm{H}_{\mathrm{O}}\right)$, gene diversity $\left(\mathrm{H}_{\mathrm{S}}\right)$ within the sampling sites were calculated with FSTAT 2.9.4 (Goudet 1995) for each site and all individual loci (Tables 1 and 2). $\mathrm{F}_{\mathrm{IS}}$ and $\mathrm{F}_{\mathrm{ST}}$ values were calculated according to Weir and Cockerham (1984). Pairwise $\mathrm{F}_{\mathrm{ST}}$ values between sampling sites were calculated and $p$-values were obtained after 3,000 permutations using FSTAT 2.9.4, pairwise Jost's D (Jost 2008) values were calculated in R 3.5.2 (R Core Team 2020) with the package PopGenReport version 3.0.4 (Table 3). A test for departure from Hardy-Weinberg equilibrium was also carried out with FSTAT 2.9.4 using 21,000 randomisations.

Isolation by Distance (IBD) pattern was investigated using Mantel's test $\left(10^{4}\right.$ replicates) with the package ade4 (Dray and Dufour 2007) in R 3.5.2. The genetic distance for this analysis was calculated using Edward's distance (Euclidean), implemented in the package adegenet (Jombart 2008) also in R 3.5.2.

Genetic structure was analysed using a Bayesian clustering approach implemented in the software STRUCTU RE 2.3.4 (Pritchard et al. 2000; Falush et al. 2003). The admixture model with correlated allele frequencies was

Table 3 Pairwise $\mathrm{F}_{\mathrm{ST}}$ and Jost's $\mathrm{D}$ values. ** indicates significance $\mathrm{p}<0.01$ and $* \mathrm{p}<0.05$, after 3,000 permutations

\begin{tabular}{llllll}
\hline & Port & & & Area2 & \\
\cline { 2 - 3 } \cline { 5 - 6 } & $\mathrm{F}_{\mathrm{ST}}$ & Jost's D & & $\mathrm{F}_{\mathrm{ST}}$ & Jost's D \\
\hline Area 2 & $0.0793^{* *}$ & 0.251 & & 0.0000 & 0.000 \\
Area 3 & $0.0456^{*}$ & 0.149 & & $0.0642^{* *}$ & 0.179 \\
\hline
\end{tabular}

run with 200,000 Markov chain Monte Carlo interactions for 10 runs, after a burn-in period of 1,000,000 and number of clusters ranging $K=1$ to 4 . The output file from STRUCTURE was used in STRUCTURE HARVESTER v0.6.94 (Earl and vonHoldt 2012) to calculate $\Delta K$ values (the rate of change in the log probability of data between successive $K$ values) as suggested by Evanno et al. (2005). Individual membership assignments estimated in STRU CTURE were aligned by CLUMPP 1.1.2 (Jakobsson and Rosenberg 2007) and DISTRUCT 1.1 (Rosenberg 2004) was used to generate the bar plot (in Fig. 2).

We used the saddlepoint approximation method to genetically assign individuals using the visualization approach described by McMillan and Fewster (2017) (Fig. 3) and also performed a principal components analysis (PCA) (Fig. 4A) on the raw genetic data using R 3.5.2 with the package geneplot v0.1.0 (McMillan and Fewster 2017). Discriminant analysis of principal component (DAPC) (Fig. 4B) was also used to assess genetic clustering with the package adegenet (Jombart 2008) in R 3.5.2. DAPC relies on data transformation using PCA as a prior step to discriminant analysis and is particularly well suited to assess between-groups variability minimizing variation within the groups, while PCA aims to summarize the overall variability among individuals (Jombart et al. 2010).

\section{Results}

Our study included a total of 71 individuals: 25 from the Port area (20 carcasses collected by the zoonosis control team and 5 captured in live traps), 24 from Area 2 (11 carcasses found in the area and 13 captured in live traps) and 22 from the Area 3 (11 carcasses found in the area and 11 captured in live traps). Overall we were able to amplify and genotype 656 of the 781 aimed loci (genotyping success of $83.9 \%$ ). As expected, the Port sampling site was more 
Fig. 2 STRUCTURE plot using the admixture model. Estimated proportion of cluster membership for each rat. The most likely structure of $K=2$ across 10 replicates was indicated by STRUCTURE HARVESTER

Fig. 3 GenePlots for Norway rats in Paranaguá. (A) Genetic assignment for individuals from Port, Area 2 and Area 3 to reference populations Port and Area 2. (B) Genetic assignment for individuals from Port and Area 3 to reference populations Port and Area 3
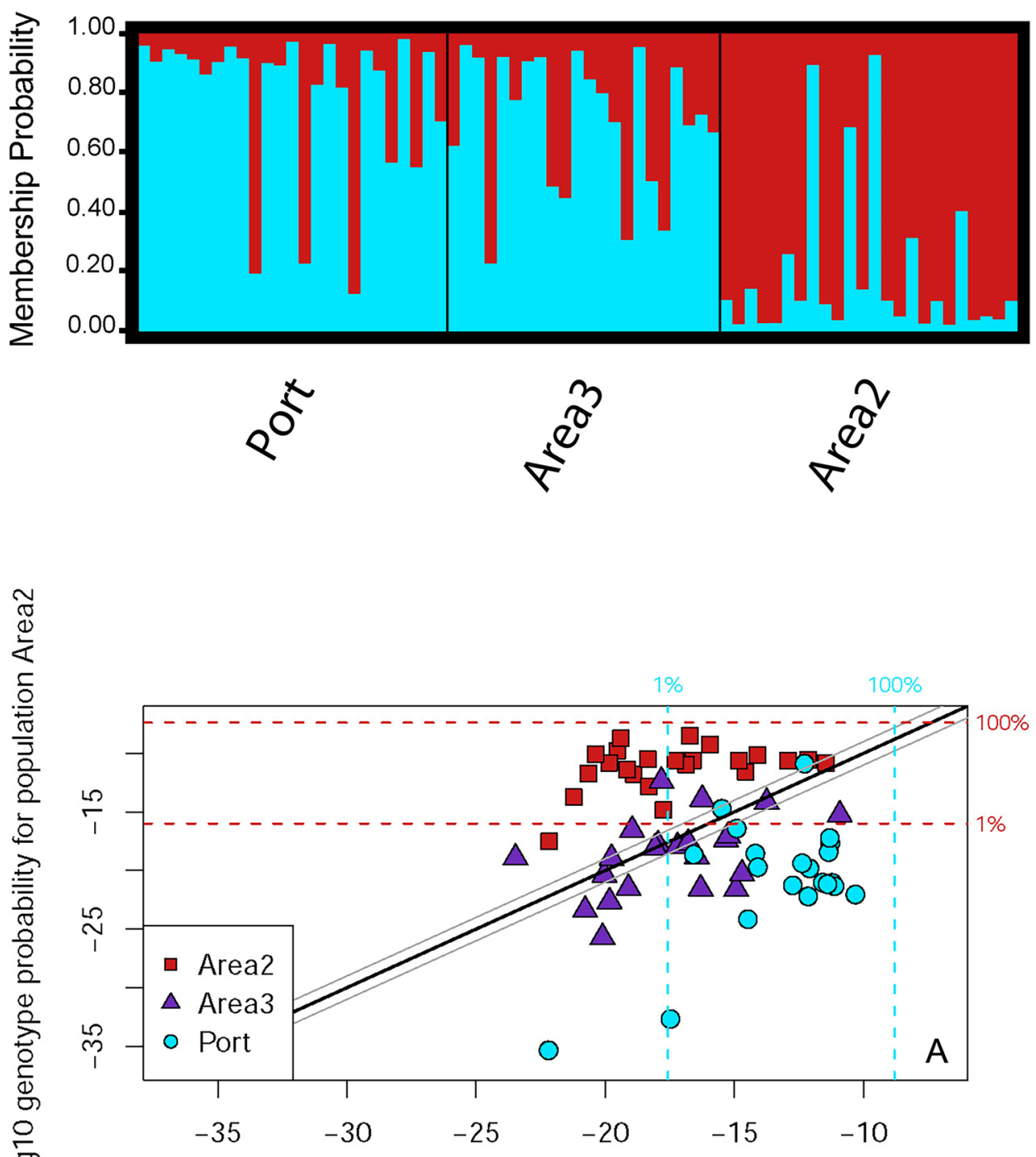

Log10 genotype probability for population Port

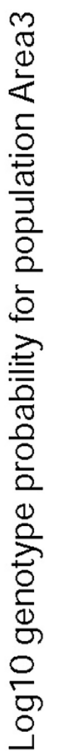

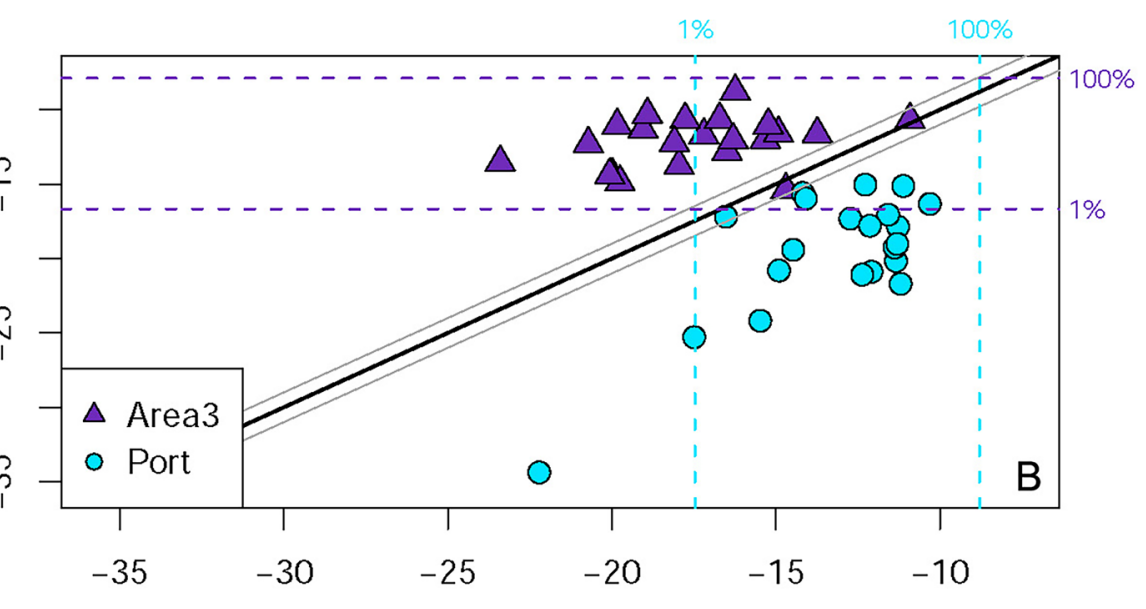

Log10 genotype probability for population Port 

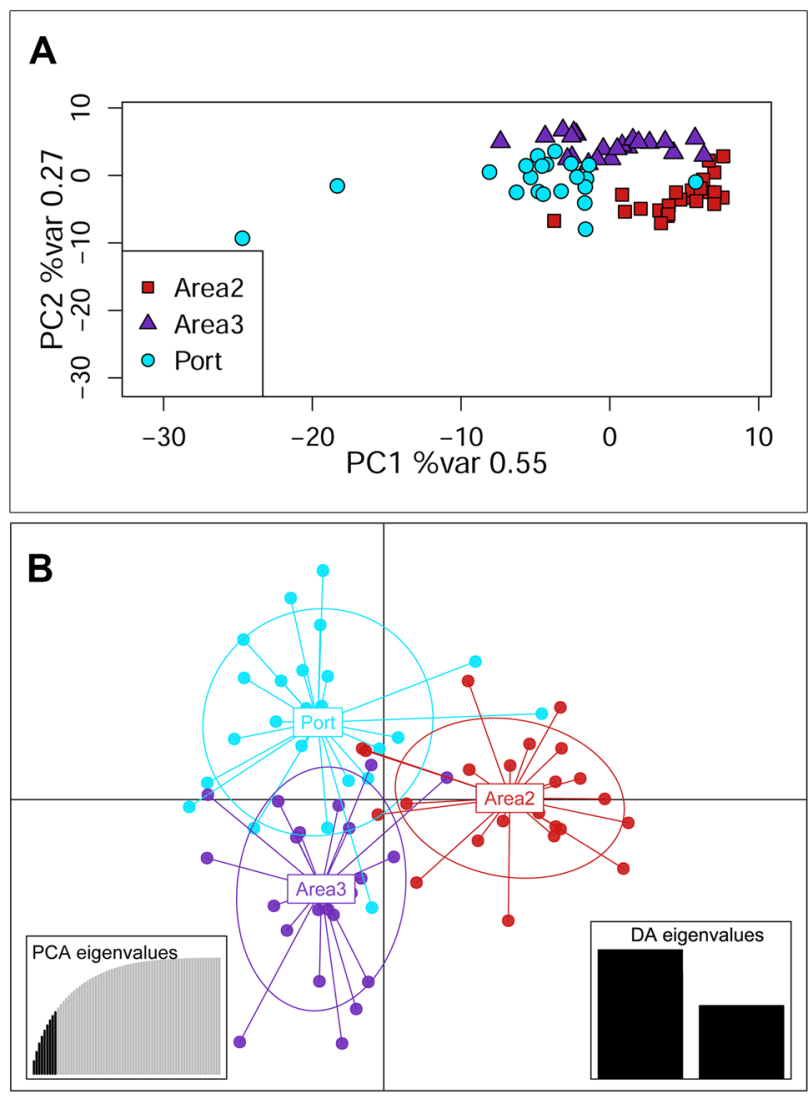

Fig. 4 Principal Component Analysis (PCA). (A) PCA using the three populations as reference accounting for a total of $82 \%$ variance explained. (B) Discriminant Principal Component Analysis (DAPC), showing the first two discriminant axes; $\mathrm{K}=3$ was identified as the optimal number of clusters, each indicated by different colours and inertia ellipses

diverse, as evident by the number of alleles $(\mathrm{n}=79)$, compared to 66 and 76 alleles for Area 2 and Area 3 respectively. Other indexes showed a similar pattern: allelic richness $(\mathrm{Ar}=6.528)$, gene diversity $\left(\mathrm{H}_{\mathrm{S}}=0.782\right)$ and observed heterozygosity $\left(\mathrm{H}_{\mathrm{O}}=0.784\right)$ were highest for the Port (Table 1). Port also showed a very low $\mathrm{F}_{\mathrm{IS}}$ value $(-0,003)$, suggesting that this is the least inbred site among the three analysed. Interestingly, samples from Area 2, which is $2 \mathrm{~km}$ away from the Port, showed less genetic diversity than individuals sampled in Area 3, located $6 \mathrm{~km}$ away from the Port. Samples from Area 3 also showed similar values compared to the Port for number of alleles, allelic richness and private alleles.

Micro-Checker detected an excess of homozygotes for D12 locus, which can indicate presence of null alleles. Locus D12 was the only marker showing a significant $\mathrm{F}_{\text {IS }}$ value $\left(\mathrm{F}_{\mathrm{IS}}=0.158 *\right)$, which indicates departure from Hardy-Weinberg equilibrium (HWE) (Table 2). We performed downstream analysis with and without locus D12 (data not shown) and since inclusion of D12 did not have significant effects on the results, the final analysis is based on all 11 markers. No evidence of false alleles or allelic dropout was detected.

Mantel's test revealed no significant pattern of IBD $(\mathrm{r}=-0.71, p$-value $=0.833)$ and according to Wright's $(1978)$ criteria, the pairwise $\mathrm{F}_{\mathrm{ST}}$ values suggested moderate genetic differentiation between Port and Area $2\left(\mathrm{~F}_{\mathrm{ST}}=0.0793\right.$, $p<0.01)$ as well as between Area 2 and Area $3\left(\mathrm{~F}_{\mathrm{ST}}=0.0642\right.$, $p<0.01$ ), but only little differentiation between Port and Area $3\left(\mathrm{~F}_{\mathrm{ST}}=0.0456, p<0.05\right)$, even though Port and Area 3 were the locations that were farthest apart. The Jost's D values also produced a similar result, with Port and Area 3 having the least differentiation. These results are shown in Table 3.

The Bayesian clustering analysis performed in STRU CTURE indicated the most likely number of clusters $(K)$ was two, and further confirmed the $\mathrm{F}_{\mathrm{ST}}$ results (i.e. clustering of Area 3 and Port), and the differentiation of these two sampling sites from Area 2 (Fig. 2). The results from the saddlepoint approximation method used in GenePlots (McMillan and Fewster 2017) corroborated with the STRU CTURE results and $\mathrm{F}_{\mathrm{ST}}$ values, indicating greater genetic similarity between Port and Area 3 than between Port and Area 2. The genetic assignment of individuals using Area 2 and Port as reference populations (Fig. 3A) revealed that more than half of the individuals from Area 3, lie below the tick diagonal line (Port assignment area) indicating greater posterior probability of originating from Port than Area 2. The remaining Area 3 individuals were mostly assigned over the tick diagonal line suggesting an equal probability of the individual originating from Port or Area 2. Lastly, four individuals from Area 3 were plotted above the diagonal lines implying higher probability of originating from Area 2.

Most of individuals sampled in Port were plotted below the $1 \%$ line for Area 2 (red dashed line) and therefore have good fit only for the Port population (see also Online Resource 1). By contrast, almost half of the individuals from Area 2 were nested above the Port's 1\% line (cyan dashed line) and between the $1 \%$ and $100 \%$ line for its own population, indicating that those individuals from Area 2 represents a subset of the Port population.

The genetic assignment using Area 3 and Port as reference (Fig. 3B) highlighted the relation between those two sites. Half of the represented individuals from Area 3 were allocated above the $1 \%$ line for Port line (cyan dashed line), meaning those individuals presented a good fit for both sampling sites, suggesting those Area 3 individuals most likely represent a subset of the Port area.

PCA (Fig. 4A) and DAPC ( $K=3$ ) (Fig. 4B) also showed higher associations between Port and Area 3 than between Port and Area 2. PCA detected two genetically divergent individuals from the Port location that did not fit with any of the sampled sites, which might indicate new migrants from an area outside of the sampled region. 


\section{Discussion}

Many studies of invasive rat species focus on island settings and serve often as eradication assessment (i.e. investigating the eradication viability or its success by verifying the survivor versus reinvader scenario)(e.g. Savidge et al. 2012; Pichlmueller and Russell 2018; Gatto-Almeida et al. 2020b). As pest eradication (i.e. complete removal of all rats) is not feasible on a continental scale, we aimed at gaining a better understanding of rat dispersal in urban areas, which can help to develop and refine management strategies.

In this study we genetically characterized $R$. norvegicus populations in a Brazilian port city, considering a busy road as a dispersal axis. The aim was to evaluate how effective the control measures were in the port area. The samples were collected from three sites along one of the main roads used by trucks to access the port in Paranaguá and results indicated that both areas outside the port presented individuals with good fit to Port population. Additionally, our samples did not show significant IBD pattern $(r=-0.71, p$-value $=0.833)$, and even suggested greater genetic similarity between the furthest apart areas, Port and Area 3, while the central location (i.e. Area 2) expected to be more similar to Area 3, if control measures in Port were effective, showed moderate genetic differentiation from the other two.

Roads are known key pathways for the spread of IAS (Brown et al. 2006; Cameron and Bayne 2009) and this spread can occur via self-dispersion (e.g. displacement by walking or swimming) (Innes et al. 2010; Russell et al. 2010; Brown et al. 2006) or human-mediated dispersion, usually associated with long distance dispersal (e.g. transport by vehicles) (Von Der Lippe and Kowarik 2007). Berthier et al. (2016), for example, found that a road network heavily used by trucks for commercial operations facilitates passive dispersal of black rats over long distances through unfavourable landscapes in south-western Niger.

Our target species, $R$. norvegicus, is known to exhibit strong site fidelity and low frequency of long-distance dispersal $(>500 \mathrm{~m}$ ) in urban environments, especially if food and harbourage are available (Gardner-Santana et al. 2009; Combs et al. 2018; Byers et al. 2019). Hence on the spatial scale of our sampling $(6 \mathrm{~km})$, assuming only self-dispersion of Norway rats, we expected to observe an IBD pattern if the control measures in port were not being effective. Individuals from the two closest sampling areas (Port and Area 2) were expected to be more genetically similar and the furthest apart populations (Port and Area 3) would show greater differentiation, as reported by Gardner-Santana et al. (2009) for Norway rats population in Baltimore (East coast, USA).
In Baltimore, the sampled populations were $0.07-13.4 \mathrm{~km}$ apart and their pairwise $\mathrm{F}_{\mathrm{ST}}$ values increased as the pairwise distance between areas increased (Gardner-Santana et al. 2009). In France, Desvars-Larrive et al. (2019) also found IBD pattern for two out of three sampled municipalities, but in contrast with those findings, our analysis suggests that the genetic patterns of rats from the two furthest apart sampling areas (Port-Area 3) are more similar, than between either Port-Area 2 or Area 2-Area 3, indicating that rats, in Paranaguá, disperse not only by self-dispersion, but also by human assistance.

Genetic assignment using GenePlots supports this idea as more than $50 \%$ of Area 3 individuals showed a good fit for the Port population, while only a few were assigned with confidence to Area 2. Vice versa, four individuals from Port had a good fit for Area 3, suggesting that gene flow occurs in both directions, although it is probably more likely to have individuals from the Port arriving in Area 3, considering GenePlot also suggests Area 3 as a subset of Port.

When individuals from just one of two populations display a good fit to both populations, it suggests that this population is a subset of the other (McMillan and Fewster 2017), like we registered between Port and Area 3. This pattern was also observed in comparison between Port and Area 2. The most likely explanation for these subsetting results is that individuals from the Port location were introduced to Area 2 and Area 3 (i.e. individuals coming from Port established in Area 2 and 3), but a different frequency and/or number of new migrants arriving in the respective areas could explain the difference in genetic differentiation observed.

The Area 2 population possibly received fewer immigrants and hence has undergone a bottleneck, resulting in the loss of alleles. This was reflected in lower diversity indices, such as the lower number of private alleles, number of alleles and allelic richness. In contrast, Area 3 appears to have received new immigrants more frequently, resulting in higher genetic diversity and more genetic similarity to the founder population (Port).

Overall, all three populations showed reasonably genetic distinctions highlighted by the differentiation indexes (Table 3 ) and by PCA and DAPC plots (Fig. 4). These are congruent with previous studies that evaluated $R$. norvegicus populations in urban environments and found long-distance dispersal occuring at low frequency (Gardner-Santana et al. 2009; Byers et al. 2019). Despite of that, we were also able to register human-mediated transport between two populations of rats $6 \mathrm{~km}$ apart. These results suggest that besides self-dispersion, human-mediated dispersion could play an important role in the dispersal dynamics of $R$. norvegicus in Paranaguá. Most of Area 3 samples were collected near a gas station where truck drivers stay overnight with loaded trucks (either coming out or going to the Port). Trucks can accidentally transport rats, 
just like vessels (Sanu and Newport 2010) and any area constantly being accessed by these modes of transportation (i.e. gas station) is susceptible to the arrival of new immigrants, facilitating gene flow between populations.

Human-mediated dispersal was also proposed to cause the absence of patterns of isolation by distance in brown rats in eastern France (Desvars-Larrive et al. 2019). The study sampled one urban and two rural municipalities and found a weak IBD pattern between the urban habitat and one of the rural municipalities, while Saint-Romain-de-Popey, the other rural municipality, showed an absence of correlation between genetic diversity and geographical distances. The authors argue that this departure is expected when dispersal between sites is rare or/and when passive dispersal (humanmediated) occurs. They however did not evaluate which human routes could have been involved in dispersal.

On a larger scale, Berthier et al. (2016) evaluated Rattus rattus dispersal between cities apart in Niger (103 to $285 \mathrm{~km}$ distance). The authors did not find patterns of IBD between the cities, but DAPC analysis and $\mathrm{F}_{\mathrm{ST}}$ values revealed greater genetic similarity between cities connected by roads, even between those furthest apart.

To summarise, our data indicates that even with control measures implemented by the Port authorities, it was not sufficient to prevent dispersal of rats from the Port to surrounding areas and vice versa. The road that we evaluate seems to be an important pathway to $R$. norvergicus dispersal in Paranaguá and therefore should be kept under pest surveillance, to prevent rats from boarding when loaded trucks park on the road, as much as trucks' cargo to prevent contaminated cargo to be loaded.

\section{Conclusions}

This study is, to our knowledge, the first to explore the role of roads in human-mediated dispersal of Norway rats inside an urban environment in America. Trucks serve as the most probable vector of rat dispersal in the studied area and vehicles can be carrying high number of individuals out of the port and facilitating the establishment of new colonies and invading new areas along the roads in Paranaguá city. Traffic out of the Port area is increasing and hence rat dispersal is expected to occur at increased rates. Therefore, we suggest stronger cargo surveillance, especially when transporting grains and other perishable goods. This would not only lower the risk of unintended rodent dispersal out of the Paranaguá Port, but also avoid cargo contamination by rat droppings and subsequently the potential spread of zoonotic disease. Members of the genus Rattus, notoriously known as reservoir for plague, leptospirosis and hantavirus, have been crucial in the circulation of such diseases in densely populated areas. Often emergence or re-emergence of these diseases is linked to rat dispersal and human activities overlapping in shared habitats. Such contaminations not only pose a risk to human and animal health, they are also a financial burden for cargo companies if the goods are spoiled.

Supplementary information The online version contains supplementary material available at https://doi.org/10.1007/s11252-021-01171-x.

Acknowledgements We would like to thank Administração dos Portos de Paranaguá e Antonina (APPA) for granting access to rat carcasses inside the port, and all the other establishments that allowed us to install traps inside their facilities.

Author contribution FGA, LMT and IH conceived and designed the research. FGA and TMD collected the data. FGA, AAS and TMD conducted experiments. FGA and FP analysed data. FGA, LMT, FP and IH wrote the manuscript. All authors read and approved the manuscript.

Funding This study was financed in part by the Coordenação de Aperfeiçoamento de Pessoal de Nível Superior - Brasil (CAPES) - Finance Code 001

Data availability Additional information can be found in the electronic supplementary material. The microsatellite data file is available in the Figshare digital repository and can be accessed at: https://doi.org/10. 17608/k6.auckland.12363914.

\section{Declarations}

Ethical approval Animal handling followed the procedures recommended by UFPR ethics committee (CEUA No 1211).

Consent to participate Not applicable.

Consent for publication Not applicable.

Conflicts of interest The authors declare that there is no conflict of interest.

Open Access This article is licensed under a Creative Commons Attribution 4.0 International License, which permits use, sharing, adaptation, distribution and reproduction in any medium or format, as long as you give appropriate credit to the original author(s) and the source, provide a link to the Creative Commons licence, and indicate if changes were made. The images or other third party material in this article are included in the article's Creative Commons licence, unless indicated otherwise in a credit line to the material. If material is not included in the article's Creative Commons licence and your intended use is not permitted by statutory regulation or exceeds the permitted use, you will need to obtain permission directly from the copyright holder. To view a copy of this licence, visit http://creativecommons.org/licenses/by/4.0/.

\section{References}

ANTAQ - Agência Nacional de Transportes Aquaviários (2020) Estatístico Aquaviário. In: Anúario. http://web.antaq.gov.br/ ANUARIO/. Accessed 9 Jun 2020

APPA - Administração dos Portos de Paranaguá e Antonina (2016) VI Relatório de Acompanhamento Ambiental - LO n ${ }^{\circ}$ 1173/2013 Regularização ambiental do Porto Organizado de Paranaguá 
APPA - Administração dos Portos de Paranaguá e Antonina (2019) História do Porto de Paranguá. In: Adm. dos Portos Parana. e Antonina. http://www.portosdoparana.pr.gov.br/modules/conteudo/ conteudo.php?conteudo=26. Accessed 22 Apr 2019

Berthier K, Garba M, Leblois R et al (2016) Black rat invasion of inland Sahel: insights from interviews and population genetics in south-western Niger. Biol J Linn Soc 119:748-765. https://doi. org/10.1111/bij.12836

Brown GP, Phillips BL, Webb JK, Shine R (2006) Toad on the road : Use of roads as dispersal corridors by cane toads (Bufo marinus ) at an invasion front in tropical Australia. Biol Conserv 133:88-94. https://doi.org/10.1016/j.biocon.2006.05.020

Byers KA, Lee MJ, Patrick DM, Himsworth CG (2019) Rats about town: a systematic review of rat movement in urban ecosystems. Front Ecol Evol 7:1-12. https://doi.org/10.3389/fevo.2019.00013

Cameron EK, Bayne EM (2009) Road age and its importance in earthworm invasion of northern boreal forests. J Appl Ecol 46:28-36. https://doi.org/10.1111/j.1365-2664.2008.01535.x

Combs M, Byers KA, Ghersi BM et al (2018) Urban rat races: spatial population genomics of brown rats (Rattus norvegicus) compared across multiple cities. Proc R Soc B Biol Sci 285(1880):20180245

Desvars-Larrive A, Hammed A, Hodroge A et al (2019) Population genetics and genotyping as tools for planning rat management programmes. J Pest Sci 92:691-705. https://doi.org/10.1007/ s10340-018-1043-4

Drake DR, Hunt TL (2009) Invasive rodents on islands: Integrating historical and contemporary ecology. Biol Invasions 11:14831487. https://doi.org/10.1007/s10530-008-9392-1

Drake JM, Lodge DM (2004) Global hot spots of biological invasions: evaluating options for ballast-water management. Proc r Soc b Biol Sci 271:575-580. https://doi.org/10.1098/rspb.2003.2629

Dray S, Dufour AB (2007) The ade4 package: Implementing the duality diagram for ecologists. J Stat Softw 22:1-20. https:// doi.org/10.18637/jss.v022.i04

Earl DA, vonHoldt BM (2012) STRUCTURE HARVESTER: A website and program for visualizing STRUCTURE output and implementing the Evanno method. Conserv Genet Resour 4:359-361. https://doi.org/10.1007/s12686-011-9548-7

Evanno G, Regnaut S, Goudet J (2005) Detecting the number of clusters of individuals using the software STRUCTURE: A simulation study. Mol Ecol 14:2611-2620. https://doi.org/10. 1111/j.1365-294X.2005.02553.x

Falush D, Stephens M, Pritchard JK (2003) Inference of population structure using multilocus genotype data: Linked loci and correlated allele frequencies. Genetics 164:1567-1587. https://doi. org/10.1111/j.1471-8286.2007.01758.x

Gardner-Santana LC, Norris DE, Fornadel CM et al (2009) Commensal ecology, urban landscapes, and their influence on the genetic characteristics of city-dwelling Norway rats (Rattus norvegicus). Mol Ecol 18:2766-2778. https://doi.org/10.1111/j.1365-294X.2009.04232.x

Gatto-Almeida F, Ferreguetti ÁC, Pontes JDS et al (2020a) The atlantic forest as a barrier to invasive rodents: Study of a seaport in Southern Brazil. Hystrix. Ital J Mammal 31:1-7. https://doi. org/10.4404/hystrix-00282-2020

Gatto-Almeida F, Pichlmueller F, Micheletti T et al (2020b) Using genetics to plan black rat (Rattus rattus) management in Fernando de Noronha archipelago. Brazil Perspect Ecol Conserv 18:44-50. https://doi.org/10.1016/j.pecon.2020.01.001

Goudet J (1995) FSTAT (version 1.2): a computer program to calculate F-statistics. J Hered 86:485-486

Gren I-M (2008) Economics of alien invasive species management - Choices of targets and policies. Boreal Environ Res 13:17-32

Himsworth CG, Parsons KL, Jardine C, Patrick DM (2013) Rats, cities, people, and pathogens: a systematic review and narrative synthesis of literature regarding the ecology of rat-associated zoonoses in urban centers. Vector Borne Zoonotic Dis 13:349359. https://doi.org/10.1089/vbz.2012.1195

Innes J, King CM, Bridgman L et al (2010) Effect of grazing on ship rat density in forest fragments of lowland Waikato, New Zealand. N Z J Ecol 34:227-232

Jacob HJ, Brown DM, Bunker RK et al (1995) A genetic linkage map of the laboratory rat, Rattus norvegicus. Nat Genet 9:63-69. https://doi.org/10.1038/ng0195-63]

Jakobsson M, Rosenberg NA (2007) CLUMPP: A cluster matching and permutation program for dealing with label switching and multimodality in analysis of population structure. Bioinformatics 23:1801-1806. https://doi.org/10.1093/bioinformatics/btm233

Jombart $\mathrm{T}$ (2008) adegenet: a R package for the multivariate analysis of genetic markers. Bioinformatics 24:1403-1405. https://doi. org/10.1093/bioinformatics/btn129

Jombart T, Devillard S, Balloux F (2010) Discriminant analysis of principal components: a new method for the analysis of genetically structured populations. BMC Genet 11:1-15. https://doi. org/10.1371/journal.pcbi.1000455

Jost L (2008) GST and its relatives do not measure differentiation. Mol Ecol 17:4015-4026. https://doi.org/10.1111/j.1365-294X. 2008.03887.x

Levine JM (2008) Biological invasions. Curr Biol 18:57-60

Lodge DM, Williams S, MacIsaac HJ et al (2006) Biological invasions: recommendations for U.S. policy and management. Ecol Appl 16:2035-2054. https://doi.org/10.1890/04-0922

McMillan LF, Fewster RM (2017) Visualizations for genetic assignment analyses using the saddlepoint approximation method. Biometrics 73:1029-1041. https://doi.org/10.1111/biom.12667

Miller LP, Blumenthal DM, Sorte CJB et al (2016) Global threats from invasive alien species in the twenty-first century and national response capacities. Nat Commun 7:1-9. https://doi. org/10.1038/ncomms 12485

Myers JH, Simberloff D, Kuris AM, Carey JR (2000) Eradication revisited: Dealing with exotic species. Trends Ecol Evol 15:316-320. https://doi.org/10.1016/S0169-5347(00)01914-5

Nei M (1987) Molecular Evolutionary Genetics. Columbia University Press, New York

Parker IM, Lonsdale WM, Goodell K et al (1999) Impact: toward a framework for understanding the ecological effects of invaders. Biol Invasions 1:3-19

Pichlmueller F, Russell JC (2018) Survivors or reinvaders? Intraspecific priority effect masks reinvasion potential. Biol Conserv 227:213-218. https://doi.org/10.1016/j.biocon.2018.09.020

Pimentel D, Lach L, Zuniga R, Morrison D (2000) Environmental and Economic Costs of Nonindigenous Species in the United States. Bioscience 50:53-65. https://doi.org/10.1641/00063568(2000)050[0053:EAECON]2.3.CO;2

Pritchard JK, Stephens M, Donnelly P (2000) Inference of population structure using multilocus genotype data. Genetics 155:945-959

R Core Team (2020) R: A language and environment for statistical computing. R Foundation for Statistical Computing, Vienna, Austria, 3.5.2, R Project

Rosenberg NA (2004) DISTRUCT: A program for the graphical display of population structure. Mol Ecol Notes 4:137-138. https:// doi.org/10.1046/j.1471-8286.2003.00566.x

Russell JC, Miller SD, Harper GA et al (2010) Survivors or reinvaders? Using genetic assignment to identify invasive pests following eradication. Biol Invasions 12:1747-1757. https://doi.org/10. 1007/s10530-009-9586-1

Sanu PV, Newport JK (2010) Invasive alien species dispersal: The millennium biodiversity disaster. Disaster Prev Manag an Int J 19:291-297. https://doi.org/10.1108/09653561011052475

Savidge JA, Hopken MW, Witmer GW et al (2012) Genetic evaluation of an attempted Rattus rattus eradication on Congo Cay, U.S. Virgin Islands, identifies importance of eradication 
units. Biol Invasions 14:2343-2354. https://doi.org/10.1007/ s10530-012-0233-x

Schuelke M (2000) An economic method for the fluorescent labeling of PCR fragments. Nat Biotechnol 18:233-234. https://doi.org/ $10.1038 / 72708$

Van Oosterhout C, Hutchinson WF, Wills DP, Shipley P (2004) MICRO-CHECKER: software for identifying and correcting genotyping errors in microsatellite data. Mol Ecol Notes 4:535-538

Varnham K (2010) Invasive rats on tropical islands: their history, ecology, impacts and eradication. Royal Society for the Protection of Birds, Sandy, Bedfordshire, UK
Von Der Lippe M, Kowarik I (2007) Long-distance dispersal of plants by vehicles as a driver of plant invasions. Conserv Biol 21:986996. https://doi.org/10.1111/j.1523-1739.2007.00722.x

Weir BS, Cockerham CC (1984) Estimating F-statistics for the analysis of population structure. Evolution (n y) 38:1358. https://doi.org/ $10.2307 / 2408641$

Wright S (1978) Evolution and the genetics of populations, volume 4: variability within and among natural populations. University of Chicago Press 